\title{
Três Gerações de Políticas Públicas para a Agricultura Familiar e Formas de Interação entre Sociedade e Estado no Brasil
}

\author{
Catia Grisa ${ }^{1}$ e Sergio Schneider ${ }^{2}$
}

Resumo: Este artigo analisa a trajetória de construção de políticas públicas para a agricultura familiar no Brasil, procurando enfatizar as "gerações" ou referenciais de políticas públicas fortalecidos em alguns momentos-chaves, o modo como estes referenciais foram construídos e as relações entre Estado e sociedade civil. A análise aponta para a emergência, em períodos e contextos distintos, de três gerações ou referenciais de política pública para a agricultura familiar, sendo o primeiro pautado pelo fortalecimento do viés agrícola e agrário da categoria social; o segundo focado em políticas sociais e assistenciais e o terceiro, pela construção de mercados orientados pela segurança alimentar e pela sustentabilidade ambiental. Nesta análise também é destacado que as relações entre Estado e sociedade civil modificaram-se e complexificaram-se ao longo do tempo. De posturas críticas e reivindicativas, a sociedade civil passou a ser propositiva e, mais recentemente, também parceira na execução e cogestão das políticas públicas. Cabe destacar que as três gerações de políticas públicas e as diversas formas de relacionamento entre sociedade civil e Estado convivem atualmente nas arenas públicas.

Palavras-chaves: Políticas públicas, agricultura familiar, referencial, sociedade civil e Estado.

Abstract: This article aims to analyze the trajectory of construction of public policies for family farming in Brazil, trying to emphasize the "generation" or public policy referentials strengthened in some key moments, the way these benchmarks were built and the relations between state and civil society. The analysis points to the emergence, in different periods and contexts, of three generations or public policy benchmarks for family farming, the first being guided by strengthening the agricultural and agrarian bias of these social group; the second focusing on social and welfare policies, and the third, by building market devices

1. Doutora em Ciências Sociais (CPDA/UFRRJ) e Mestre em Desenvolvimento Rural (PGDR/UFRGS). Professora no programa de Pós-graduação em Desenvolvimento Territorial e Sistemas Agroindustriais (PPGDTSA) na Universidade Federal de Pelotas (UFPel). E-mail: catiagrisa@yahoo.com.br

2. Doutor e Mestre em Sociologia. Professor no programa de Pós-Graduação em Sociologia (PPGS) e no programa de Pós-graduação em Desenvolvimento Rural (PGDR), ambos na Universidade Federal do Rio Grande do Sul. E-mail: schneide@ufrgs.br 
for food and nutritional security and enviromental sustainability. This analysis also highlights that the relations between state and civil society have changed and become more complex over time. From criticism and claiming positions, civil society actors came to be proactive and, more recently, also a partner in the implementation and management public policies. It is noteworthy that the three generations of public policies and various forms of relationship between civil society and state follow and coexist in public arenas till today.

Key-words: Public policies, family farming, referential, civil society, and Sate.

Classificação JEL: Q18.

\section{Introdução}

Mudanças importantes ocorreram no cenário político institucional e nas dinâmicas sociais nos últimos 20 anos no Brasil. O marco inicial destas transformações pode ser fixado a partir da promulgação da nova Constituição que rege o tecido jurídico e societário brasileiro na atualidade. Todavia, fixar uma marca temporal é sempre complicado quando se trata de entender os processos sociais e suas mudanças, especialmente quando sabemos das interfaces entre passado e presente.

Neste período recente que compreende as três últimas décadas, novas relações entre Estado e sociedade civil foram estabelecidas, espaços de participação social foram criados, novos atores políticos emergiram e foram reconhecidos como sujeitos de direito, criaram-se regras e instrumentos de política pública que foram institucionalizados, e novos referenciais globais e setoriais orientaram as ações do Estado e permitiram redefinir regras e compreensões que afetaram mais ou menos as condições socioeconômicas da população, especialmente a do meio rural. Estes são alguns exemplos das mudanças iniciadas nas últimas três décadas e, em grande medida, ainda em curso. Como protagonista e objeto de muitas destas mudanças destaca-se a agricultura familiar, uma categoria social e política que passou a ser reconhecida pelo Estado brasileiro em meados de 1990.
$\mathrm{O}$ reconhecimento conferido à agricultura familiar e a construção de políticas diferenciadas para um vasto grupo social que até então não havia sido contemplado com ações específicas não foram mudanças triviais, e é por isto que ganharam repercussões no cenário nacional e internacional. Vale notar, como destacado por Abramovay e Morello (2010), que este processo ocorreu porque o

fortalecimento da democracia está na raiz das mais importantes mudanças pelas quais passa o meio rural brasileiro nos últimos 20 anos [...] que permitiram reduzir a pobreza de sua população, melhorar a distribuição de renda e dar início a mudanças de comportamento empresarial no sentido de fazer do bem-estar das pessoas e da resiliência dos ecossistemas a base da própria vida econômica.

Historicamente, a agricultura familiar ou "os pequenos agricultores" - como eram denominados até cerca de duas décadas atrás - sempre estiveram às margens das ações do Estado brasileiro, não raro incrementando sua fragilidade diante das opções de desenvolvimento perseguidas no País. Iniciando uma nova trajetória para a categoria social, a Constituição de 1988 incitou novos espaços de participação social e reconheceu direitos; a criação do Programa Nacional de Fortalecimento da Agricultura (Pronaf) em 1995 desencadeou a emergência de outras políticas diferenciadas de desenvolvimento rural; a criação 
do Ministério do Desenvolvimento Agrário (MDA) em 1999, e da Secretaria da Agricultura Familiar (SAF) no interior deste em 2001, institucionalizaram a dualidade da estrutura agrária e fundiária no País; e em 2006, foi regulamentada a Lei da Agricultura Familiar que reconheceu a categoria social, definiu sua estrutura conceitual e passou a balizar as políticas públicas para este grupo social. Não raro, o Brasil é destacado por organizações internacionais multilaterais pela estrutura política e institucional que construiu ao longo dos anos para a agricultura familiar, cujos formatos, objetivos e políticas têm sido "exportados" para outros países.

O objetivo deste artigo consiste em analisar esta trajetória de reconhecimento da agricultura familiar, procurando enfatizar as "gerações" ou referenciais de políticas públicas fortalecidos em alguns momentos-chaves, o modo como estes referenciais foram construídos, e as relações entre Estado e sociedade civil. Este exercício analítico dialoga com diferentes abordagens teóricas, destacando-se as contribuições da abordagem cognitiva de análise de política pública, nomeadamente as elaborações de Pierre Muller, Bruno Jobert e Ève Fouilleux. Estes autores enfatizam o papel das ideias na construção das políticas públicas, sendo estas elaboradas a partir das crenças comuns e de representações de mundo de um conjunto de atores (públicos e privados), as quais definem a maneira como estes percebem os problemas públicos e concebem respostas aos mesmos (GRISA, 2012; FOUILLEUX, 2011; 2003; MULLER, 2008; SUREL, 2000; JOBERT e MULLER, 1987). As políticas públicas refletem, portanto, o entendimento dos grupos sociais sobre sua própria condição e sobre a sociedade em geral, bem como sobre os instrumentos necessários para aperfeiçoar esta condição ${ }^{3}$.

3. O que não implica em deconsiderar que outros elementos também interferem na conformação das políticas públicas, a exemplo das instituições e dos interesses (PALIER e SUREL, 2005; PIERSON, 2003; MAHONEY, 2001; HALL, 1997). Trata-se aqui de dar ênfase em alguns elementos explicativos, no caso, o papel das ideias.
Três conceitos são particularmente importantes nesta análise: referencial global, referencial setorial e referencial de política pública. O referencial global está relacionado a um quadro geral de interpretação do mundo, superando os limites de um setor, de um domínio ou de uma política (MULLER, 2005). Trata-se da “[...] representação que uma sociedade faz da sua relação com o mundo em um momento dado" (MULLER, 2008, p. 65), e é em torno desta representação geral que serão hierarquizadas as diferentes representações setoriais, sendo que o referencial global não constitui uma estrutura cognitiva e normativa unificada que se impõe de maneira mecânica ao conjunto dos domínios da vida social (econômico, político, social etc.). O referencial setorial diz respeito às representações de um setor, entendido como um conjunto de questões ou problemas associados de maneira mais ou menos institucionalizada a certas populações ou temas. Em decorrência das várias concepções sobre a natureza e a extensão dos limites de um setor, a construção do referencial setorial é um processo em permanente conflito. "Como o referencial global, o referencial de um setor é uma construção social cuja coerência nunca é perfeita" (MULLER, 2008, p. 69). Contudo, há uma representação hegemônica, amiúde coerente com o referencial global, e é esta representação que se impõe como referência à elaboração de políticas públicas.

Desta relação entre referencial global e setorial constrói-se uma representação da realidade sobre a qual se intervém, e é através desta imagem, denominada "referencial de uma política pública", que os atores interpretam o problema, confrontam possíveis soluções e definem suas ações. Há, na realidade, um duplo mecanismo permanente na construção de um referencial: primeiro, uma operação de decodificação do real com o objetivo de limitar sua complexidade e, em seguida, uma operação de recodificação para definir um programa de ação pública (MULLER, 2008). Fouillex $(2011,2003)$ define referencial de política pública como a materialização das ideias em instrumentos e na organização geral da política pública. Trata-se dos instrumentos que 
tornam efetiva a ação do Estado a partir das diferentes representações de mundo e dos problemas públicos construídos pelo conjunto de atores envolvidos na elaboração das políticas públicas. Este referencial é objeto de negociação permanente entre os protagonistas das trocas políticas, sendo suscetível de inclusões, recortes e transformações em função das relações de força e dos objetivos políticos dos diferentes atores envolvidos na construção da política pública.

É importante referir que a definição destas gerações de políticas e seus referenciais também possui um sentido heurístico, que utilizamos com o objetivo de identificar os distintos "momentos críticos" em que apareceram ou foram criadas novas formas de ação governamental. No entanto, isto não quer dizer que estas gerações de políticas possuem uma linearidade longitudinal e nem que uma geração precede a outra, como se houvesse uma ampliação de escala ou redirecionamento de enfoque. As três gerações de políticas identificadas não encerraram seu ciclo, continuam em funcionamento e seguidamente sofrem ajustes e/ou alterações em sua formulação ou escopo.

A primeira seção do artigo debate a emergência das políticas para a agricultura familiar e a conformação de um referencial de política pública agrícola e agrário. A seção seguinte apresenta os elementos que caracterizam a segunda geração de políticas para a agricultura familiar pautada em um referencial social e assistencial e como este referencial se expressa em programas e ações públicas. A terceira seção evidencia a construção e a incidência de uma nova geração de políticas públicas para a agricultura familiar sustentada na construção de novos mercados com foco na segurança alimentar e a sustentabilidade. Ao longo destas seções também são salientadas mudanças nas formas de relação e interação entre Estado e sociedade civil. O artigo é finalizado com algumas considerações sobre a vigência destes referenciais e as relações entre Estado e sociedade civil na atualidade.

\section{Primeira geração de políticas para a agricultura familiar: a construção de um referencial agrícola e agrário}

Desde a segunda metade da década de 1950, o governo brasileiro adotou de forma mais acentuada a estratégia de industrialização por substituição de importações (referencial global), como uma tentativa de superar a defasagem que separava o Brasil das economias capitalistas industrializadas (BIELSCHOWSKY, 2006, 2000). Nesta estratégia nacional-desenvolvimentista, o Estado atuou como agente produtivo por meio da criação de infraestruturas estatais; agente financeiro, promovendo a transformação da estrutura industrial; articulador de capitais privados nacionais e internacionais e formulador e executor de políticas macroeconômicas e setoriais, privilegiando a constituição de uma economia industrial (DELGADO, 2010). Todavia, no início da década de 1960, essa estratégia apresentou sintomas de crise em razão das dificuldades no abastecimento alimentar interno, do aumento da inflação (saldo da rigidez da oferta do setor agrário frente ao crescimento da demanda por produtos primários pela industrialização e urbanização), do esgotamento da capacidade de importar bens necessários à industrialização do País (que, por sua vez, demandava investimentos em exportações para criar divisas) e da emergência de críticas ao padrão dependente e excludente seguido pela industrialização (DELGADO, 2010, 1988; COELHO, 2001; CASTRO, 1984).

Desta crise, duas opções e "referenciais setoriais" aparecem na agenda pública. Reivindicada por acadêmicos (Caio Prado, Alberto Passos Guimarães, Ignácio Rangel e notadamente a vertente "cepalina estruturalista" representada por Celso Furtado), por políticos (nomeadamente o governo de João Goulart) e por movimentos sociais (Ligas Camponesas, União dos Lavradores e Trabalhadores Agrícolas do Brasil, Movimento dos Trabalhadores Sem Terra, Confederação 
Nacional dos Trabalhadores na Agricultura Contag), uma destas opções clamava por um conjunto de reformas de base, dentre elas a reforma agrária, visando dinamizar o mercado interno. Contrapondo-se a esta opção e sustentada pelas elites agrárias, por acadêmicos vinculados a economistas da Universidade de São Paulo (principalmente Antonio Delfim Neto) e por militares que tomaram o governo federal, outro referencial setorial foi institucionalizado no Brasil, orientado pela modernização tecnológica da agricultura (GRISA, 2012; DELGADO, 2005). Argumenta-se que a agricultura precisava modernizar-se para cumprir suas funções no desenvolvimento econômico do País. O ajuste entre o setor da agricultura ("referencial setorial") e a industrialização da economia do País ("referencial global") passou a ser realizado por um conjunto de ações e políticas públicas, como crédito rural, garantia de preços mínimos, seguro agrícola, pesquisa agropecuária, assistência técnica e extensão rural, incentivos fiscais às exportações, minidesvalorizações cambiais, subsídios à aquisição de insumos, expansão da fronteira agrícola, e o desenvolvimento de infraestruturas. Por cerca de 20 anos, este foi o referencial setorial predominante que orientou as ações do Estado no setor agrícola e pecuário - configurando o que Delgado (2001) denominou de "política agrícola ativa" -, o qual, como já apontado por vários estudos (DELGADO, 2010; GRAZIANO DA SILVA, 1999; GONÇALVES NETO, 1997; KAGEYAMA et al., 1990; GUEDES PINTO, 1978), apresentou um caráter triplamente seletivo, beneficiando principalmente os médios e os grandes agricultores, localizados nas regiões Sul e Sudeste, produtores de produtos direcionados à exportação ou de interesses de grupos agroindustriais (café, soja, trigo, cana-de-açúcar, laranja, algodão).

Durante os vinte anos de ditadura militar, os representantes da sociedade civil vinculados à agricultura familiar não encontraram espaço na arena pública para discutir e construir em conjunto com os gestores públicos políticas para a categoria social. O contexto político e institucional excluía a participação destes atores e limitava uma atuação mais crítica e propositiva da Contag, principal representação dos "pequenos agricultores" na época. Conforme evidenciado por Grisa (2012), a construção das políticas públicas para a agricultura resultava basicamente das representações de mundo e do setor (referencial global e setorial) oriundas de gestores públicos, acadêmicos e representantes de grupos de interesse, conformando um referencial setorial direcionado para a modernização da agricultura.

No final dos anos 1970, este cenário começou a ser alterado, sendo emblemática a mudança de posicionamento político da Contag entre o II Congresso Nacional dos Trabalhadores Rurais (1973) e o III Congresso Nacional dos Trabalhadores Rurais (1979). No II Congresso período de maior repressão da ditadura militar -, ainda que pautando a reforma agrária, o "tom" da Contag era conciliador em relação ao governo, ressaltando as conquistas já adquiridas em termos de previdência social e proteção ao trabalhador rural (CONTAG, 1973). No III Congresso, a Contag apresentou-se mais combativa e reivindicatória, cobrando insistentemente a reforma agrária e uma política agrícola adequada às particularidades dos pequenos agricultores (CONTAG, 1979a; CONTAG, 1979b). Conforme expresso no Boletim Periódico da Confederação, "hoje falamos menos em encaminhar e mais em reivindicar; não se fala mais em pedir e sim, em exigir" (CONTAG, 1979b, p. 26). As disputas no interior do sindicalismo, a emergência do "novo sindicalismo rural" e de novos movimentos sociais incrementaram esta postura reivindicativa, de protesto e crítica ao governo federal (PICOLOTTO, 2011; SCHNEIDER, 2010; FAVARETO, 2006; SCHMITT, 1996). A defesa da reforma agrária, a demanda por políticas diferenciadas e por legislação trabalhista e críticas ao regime ditatorial tornaram-se constantes nas reivindicações dos representantes da agricultura familiar.

Estas mudanças incrementaram-se com a redemocratização a partir de meados da década de 1980 e com o debate da constituinte em 1988. O processo de democratização permitiu um "intenso movimento de rearticulação e flores- 
cimento de novas organizações na sociedade civil" (SANTOS, 2011, p. 79). No âmbito da agricultura familiar, destacaram-se as mudanças na forma de atuação da Contag; a criação da Central Única dos Trabalhadores (CUT) em 1983 e, nesta, a conformação do Departamento Nacional de Trabalhadores Rurais (DNTR) em 1988; a constituição do Movimento dos Trabalhadores Sem Terra (MST) em 1984; a institucionalização do Movimento dos Atingidos por Barragens (MAB) em 1991, os quais vinham atuando desde o final da década de 1970, e a criação do Conselho Nacional dos Seringueiros (CNS) em 1985. Ainda que com objetivos ou ênfases distintas, as ações destes atores sociais tornaram visíveis as precárias condições de reprodução social dos pequenos produtores e, cada vez mais, reclamaram a intervenção do Estado na construção de políticas públicas adequadas às suas particularidades, destacando-se a reforma agrária e o crédito rural.

Neste contexto, com a abertura democrática e mudanças político-institucionais em curso, os representantes da agricultura familiar alteraram sua postura diante do Estado. As possibilidades abertas com o debate da constituinte, as negociações para a definição das Leis Agrícola e Agrária, e a emergência dos Conselhos alteraram a forma de interação entre a sociedade civil representativa dos agricultores familiares e o Estado. Os representantes da agricultura passaram a adotar estratégias propositivas e adentraram nas arenas públicas, propondo e disputando a construção das políticas públicas. Tanto a Contag quanto o DNTR/CUT elaboraram textos para a discussão com suas respectivas bases sociais sobre a reforma constituinte (CONTAG, 1988; CUT, 1989), construíram propostas de normatização para a Lei Agrícola (CONTAG, 1989; CUT, 1991) e disputaram a institucionalização das regras com outros segmentos, nomeadamente com o setor da agricultura patronal.

Algumas das demandas dos representantes da agricultura familiar foram incorporadas e institucionalizadas no momento de construção da Lei Agrícola, a qual reconheceu a diversidade dos agricultores brasileiros e previu a construção de uma política agrícola diferenciada para os pequenos produtores (MIELITZ NETTO, 2010; DELGADO, 1994). Todavia, estas conquistas ficaram aquém das reivindicações destes atores, prevalecendo as ideias, os interesses e o poder da agricultura patronal na construção das políticas públicas. Não por acaso, a Lei Agrícola institucionalizou, em grande medida, os interesses dos grandes produtores (PICOLOTTO, 2011; SANTOS, 2011; SCHMITT, 1996; DELGADO, 1994). Como lembra Delgado (1994, p. 14), contribuíram para este resultado "certo vácuo institucional" da parte do Estado para tratar das demandas dos pequenos agricultores e a cultura institucional de instituições de crédito, pesquisa, extensão e comercialização, não habituadas em incorporar em suas metodologias de atendimento as demandas deste segmento.

Também é importante destacar que, no final dos anos 1980, o Estado brasileiro vivenciava um período de intensas mudanças político-econômicas. O processo de liberalização econômica - construído a partir das ideias de um novo referencial global (o neoliberalismo) para enfrentar a crise política e financeira das décadas de 1980 e 1990 - impôs novas estratégias e instrumentos para a ação governamental: redução da intervenção do Estado, desregulamentação das atividades econômicas, privatização de companhias estatais, liberalização dos mercados etc. (SANTOS, 2011; SALLUM JR., 2003; DIAS e AMARAL, 2000). No caso da agricultura, destacam-se particularmente: (a) a liberalização comercial e o desmonte do modelo de intervenção do Estado prevalente até a década anterior, implicando em redução do volume de recursos aplicados nas políticas agrícolas, liquidação da política de formação de estoques reguladores e queda nas tarifas de importação de produtos alimentares e algodão; (b) a criação da Mercosul em 1991, que afetou negativamente sobretudo a produção agropecuária dos estados do Sul, notadamente o setor lácteo, tritícola, vitivinícola e a fruticultura, atividades típicas de pequenas propriedades, que sentiram dificuldades de competir com a produção dos países vizinhos; (c) a adoção de plano real 
em 1994, o qual provocou queda da renda real do setor agrícola de $20 \%$ a $30 \%$ no primeiro semestre de 1995; (d) a valorização da taxa de câmbio, associada ao grande volume de recursos disponíveis no sistema financeiro internacional e as elevadas taxas de juros domésticas, as quais favoreceram o aumento das importações de produtos agrícolas e o decréscimo das exportações (MATTEI, 2014; PICOLOTTO, 2011; DELGADO, 2010). Estas medidas ameaçaram as condições de reprodução social e econômica da agricultura familiar, a qual já havia sido afetada pelas consequências da modernização da agricultura.

Diante destas medidas econômicas que incrementaram a fragilidade social da categoria social, e aproveitando as possibilidades abertas com a redemocratização, os representantes da agricultura familiar recrudesceram sua postura propositiva e, por meio de mobilizações sociais expressivas (como os Gritos da Terra Brasil, cuja primeira edição foi realizada em 1994), passaram a exigir políticas específicas para a categoria, bem como a participação na construção destas. Um momento emblemático neste sentido foi a construção do documento "Propostas e recomendações de política agrícola diferenciada para o pequeno produtor rural" (BRASIL, MAARA/ CONTAG, 1994), elaborado por uma Comissão Técnica do Pequeno Produtor (Portarias Maara n. 692 de 30/11/1993 e n. 42 de 24/01/1994), no Ministério da Agricultura, do Abastecimento e da Reforma Agrária (Maara), com a participação da Contag4. Cabe salientar, como inovações deste documento, dentre outros elementos, as propostas de criação de um "Programa Especial de Crédito para os Pequenos Produtores Rurais", com encargos financeiros, prazos, carências e formas de pagamentos específicos; a implantação

4. Desde a criação do DNTR/CUT em 1988, o sindicalismo cutista viveu uma situação ambígua entre construir uma estrutura autônoma e, portanto, negar a estrutura oficial (Contag) ou aceitar em sua base os sindicatos oficiais e disputar a estrutura contaguiana (PICOLOTTO, 2011; FAVARETO, 2006). Em 1991, a CUT decidiu por compor a diretoria da Contag e, em 1995, esta filiou-se àquela. Esta unificação contribuiu para dar maior visibilidade e poder de reivindicação ao sindicalismo dos trabalhadores rurais. de um seguro agrícola destinado exclusivamente à cobertura das explorações agropecuárias dos pequenos produtores rurais; a conformação de alguns programas para fazer frente ao Mercosul; a proposição de uma definição de pequeno produtor, que balizaria a construção de políticas públicas para a categoria social; a institucionalização dessa definição via substitutivo ao Projeto de Lei ou minuta de Medida Provisória; a inclusão deste conjunto de propostas já no Plano Safra 1994/95, em especial aquelas relacionadas à definição de pequeno produtor e às políticas de crédito rural e seguro agrícola; e a criação no Maara de uma Secretaria específica que estabelecesse e coordenasse as políticas agrícolas diferenciadas (Brasil, MAARA/CONTAG, 1994).

Fruto das mobilizações sociais realizadas por movimentos sociais vinculados à agricultura familiar, de uma mudança paradigmática nos estudos rurais (que passaram a destacar a permanência e a importância da agricultura familiar nos países desenvolvidos) (SCHNEIDER, 2003; LAMARCHE, 1999, 1993; ABRAMOVAY, 1992; VEIGA, 1991), e dos próprios interesses do governo federal em manter a ordem social no campo e certa influência no sindicalismo dos trabalhadores rurais (GRISA, 2012), criou-se a primeira política agrícola nacional direcionada especificadamente para agricultores familiares. Trata-se da institucionalização do Pronaf, em 1995, que marcou o reconhecimento político e institucional do Estado brasileiro à categoria social, configurando-se um "momento crítico" (MAHONEY, 2001) ${ }^{5}$ que abriu possibilidades institucionais para a criação de novas políticas para a agricultura familiar. O Pronaf delineava-se como uma política de crédito rural que contribuiria para a capitalização e o acesso dos agricultores familiares "em transição" aos mercados, tornando-os consolidados (FAO-INCRA,

5. Este termo foi cunhado por Mahoney (2001), referindo-se ao modo como as escolhas institucionais dos atores, em momentos críticos, criam instituições que tendem a persistir e não são facilmente alteradas, orientando e condicionando o comportamento e as decisões subsequentes dos diferentes agentes envolvidos em processos concretos de produção da ruralidade. 
1994). Iniciava-se com o Pronaf a construção de um conjunto de medidas orientadas para fortalecer e garantir a produção agrícola dos agricultores familiares. A criação do Seguro da Agricultura Familiar (Seaf-2004) e do Programa de Garantia de Preço da Agricultura Familiar (PGPAF-2006) e a retomada da Assistência Técnica e Extensão Rural (Ater) pública em anos posteriores reforçariam este cenário.

É importante destacar que, em meados da década de 1990, as lutas do MST também estavam em um momento de ascensão e os conflitos agrários se acirravam. Dois fatos marcaram este período. O primeiro deles refere-se ao conflito conhecido como "Massacre de Corumbiara", ocorrido em Rondônia em meados de 1995, onde agricultores sem terra e a polícia entraram em confronto, resultando na morte de 10 pessoas. Similar a este, o segundo fato diz respeito ao "Massacre de Eldorado do Carajás", ocorrido no Pará em 1996, no qual 17 agricultores sem terra foram assassinados. Estes fatos tiveram grande repercussão nacional e internacional e, concomitante à continuidade das mobilizações sociais, desencadearam o incremento na política de assentamentos de reforma agrária, que havia ganhado um novo ímpeto com a redemocratização e a proposta do I Plano Nacional de Reforma Agrária (I PNRA), no início do governo Sarney (1985), mas, logo em seguida, foram arrefecidos pelas pressões de atores e organizações contrários a este referencial setorial. Com efeito, a criação do Pronaf e o incremento da política de assentamentos de reforma agrária surgem, em certa medida, como resposta às pressões oriundas de várias mobilizações sociais (eventos regionais, Gritos da Terra Brasil, ocupações de terra e acampamentos de reforma agrária). ${ }^{6}$

6. A criação do Pronaf também resultou de uma espécie de troca política entre governantes e representantes sindicais da agricultura familiar. Como observaram Grisa (2012) e Medeiros (2001), conceder políticas distributivas tornava-se estratégico ao governo, o qual visava amenizar e conter a contestação social e, ao mesmo tempo, manter certa influência sobre o sindicalismo rural e garantir o seu apoio eleitoral. A não adoção de medidas pelo governo federal poderia incrementar o poder de mobilização do MST, que vinha angariando crescente reconhecimento e legitimidade social, inclusive no meio urbano.
Seguindo Schneider, Shiki e Belik (2010), este é o contexto que permitira a emergência de uma primeira geração de políticas públicas para a agricultura familiar no Brasil, as quais apresentaram um referencial setorial basicamente agrícola (crédito rural, seguro de produção e de preço) e agrário (política de assentamentos de reforma agrária $)^{7}$. Estas políticas exigiram do governo e da sociedade brasileira um olhar mais atento para a importância da agricultura familiar no desenvolvimento do País e para as suas condições de reprodução social com base na terra e na produção agrícola. Como ilustra a Figura 1, a seguir, estas políticas emergiram em meados da década de 1990 e continuam vigentes atualmente, sendo reivindicadas e estando em permanente construção/aperfeiçoamento, principalmente pela retroalimentação das ideias de organizações sociais e sindicais da agricultura familiar, gestores públicos e estudiosos do mundo rural.

O Pronaf se constituiu na principal política agrícola para a agricultura familiar (em número de beneficiários, capilaridade nacional e recursos aplicados) e, historicamente, tem contado com um montante crescente de recursos disponibilizados, atingindo, no Plano Safra da Agricultura Familiar 2014/2015, o valor de R \$24,1 bilhões. Ilustrando seu viés de fortalecimento da produção agrícola, diversos estudos apontam que o programa tem beneficiado principalmente as unidades familia-

7. Cabe destacar que o referencial de política pública do Pronaf apresentava, em sua proposição inicial, coerência com o referencial global do neoliberalismo, seguido pelos governos federais (Collor, Itamar Franco e Fernando Henrique Cardoso) desde o início da década de 1990. Seguindo orientações acadêmicas, compreendia-se o programa como um mecanismo para impulsionar para os mercados os agricultores familiares que apresentassem um mínimo de condições produtivas (GUANZIROLI, 2007; BRASIL, MINISTÉRIO DA AGRICULTURA E DO ABASTECIMENTO, 1998; FAO/ INCRA, 1994; BANCO MUNDIAL, 1994). O Estado deveria intervir nas "falhas de mercado" e promover a inserção econômica destes grupos sociais. Já a política de criação de assentamentos de reforma, diferente da coerência "prevista" por Muller (2008), apresentava um referencial de política pública distinto do referencial global seguido pelo governo Fernando Henrique Cardoso. Contudo, não tardou para o governo federal tentar adequar aquele a este com a "Reforma Agrária de Mercado", como definiram diversos autores (SAUER e PEREIRA, 2005; PEREIRA, 2004; MEDEIROS, 2003). 
res de produção em melhores condições socioeconômicas, localizadas nas regiões Sul e Sudeste, e promovido o cultivo de produtos competitivos no mercado internacional, os quais são controlados por poucas empresas do sistema agroindustrial e cuja forma de produção está assentada no uso generalizado de insumos modernos. O milho e a soja respondem, desde 2001, por mais de 50\% dos recursos aplicados pelo Pronaf no custeio de lavouras (em 2002 e 2003, os dois produtos alcançaram mais de $60 \%$ ). Se somarmos os recursos aplicados no café (cultivo que apresentou importante crescimento em número de contratos e recursos no período em análise), este valor atinge cerca de $70 \%$ dos recursos aplicados no custeio de lavouras (GRISA, WESZ JR. e BUCHWEITZ, 2014).

A política de assentamentos de reforma agrária também continuou sendo realizada em anos seguintes, ainda que com importantes oscilações. Segundo dados do DataLuta (2013), a política de criação de assentamentos de reforma agrária incrementou-se de 1995 a 1997, atingindo o número de 92,99 mil famílias assentadas neste último ano, sendo que, a partir de então, os números foram reduzindo-se até 2003 , quando, no início do governo Lula, há novamente uma reação e alcança o número máximo de 104.197 famílias assentadas em 2005. Após este período, os números decrescem novamente. No segundo mandato do governo Lula e no mandato da presidente Dilma, de modo geral, os números permanecem abaixo da trajetória gerada a partir de 1995. Desde os governos Lula e (sobretudo) Dilma, o enfoque central parece ser a qualificação dos assentamentos já constituídos, melhorando as condições de infraestrutura e de produção, enquanto a criação de novos foi posta em um segundo plano, realizada fundamentalmente com a incorporação de terras públicas nas regiões Norte e Nordeste (FERNANDES, 2013; IPEA, 2012; MATTEI, 2012).

Em síntese, pode-se sinalizar que a adoção de estratégias propositivas do sindicalismo dos trabalhadores rurais, em contraposição a uma postura crítica, de protestos e reivindicações, até então prevalecente, assim como a pressão social dos movimentos sociais, foram elementos impor- tantes que contribuíram de forma decisiva para a emergência da primeira geração de políticas para a agricultura familiar, baseada em um referencial agrícola e agrário (PICOLOTTO, 2011; SCHNEIDER, 2010; FAVARETO, 2006). A participação proeminente de representantes dos agricultores familiares e de gestores vinculados ao Mapa (e, a partir de 1999, ao MDA) na construção destas políticas públicas explica, em grande medida, o referencial que orientou a elaboração das mesmas. A esta demanda social e política se somaram os estudos e resultados de pesquisas que destacavam de forma eloquente a importância econômica dos agricultores familiares nos países desenvolvidos (LAMARCHE, 1993; ABRAMOVAY, 1992; VEIGA, 1991).

Esta confluência de esforços e evidências criou as condições para que, também no Brasil, a agricultura familiar passasse a ser vista de forma positiva e relevante para a produção de alimentos e geração de empregos. A construção do Pronaf resultou do diálogo e da negociação de ideias entre três "fóruns de produção de ideias" ${ }^{8}$, conformados pelo representantes dos agricultores familiares, dos estudiosos do mundo rural e de políticos e gestores públicos (GRISA, 2012). As políticas agrícolas para a agricultura familiar desencadeadas pelo Pronaf, e a ele estritamente vinculadas (Seaf e PGPAF), resultam fundamentalmente das proposições e negociações entre gestores públicos e os representantes da agricultura familiar, que a partir de 2003 asseguraram mais um canal de diálogo com o Governo Federal por meio das discussões anuais para definição dos Planos Safra da Agricultura Familiar.

8. "Fóruns de produção de ideias" é um conceito originalmente utilizado por Jobert (1994) e discutido também por Fouilleux (2003). Referem-se aos espaços mais ou menos institucionalizados e especializados, regidos por regras e dinâmicas específicas, nos quais grupos de atores debatem visões de mundo. Coerentes com a abordagem cognitiva, compreendem-se como espaços onde as ideias são produzidas. Cada fórum é produtor de diferentes representações, ideias sobre as políticas, as quais variam segundo interesses, identidades, relações de poder e instituições. 
Figura 1. Principais grupos de atores atuantes na construção dos referenciais de política pública para a agricultura familiar ao longo dos anos

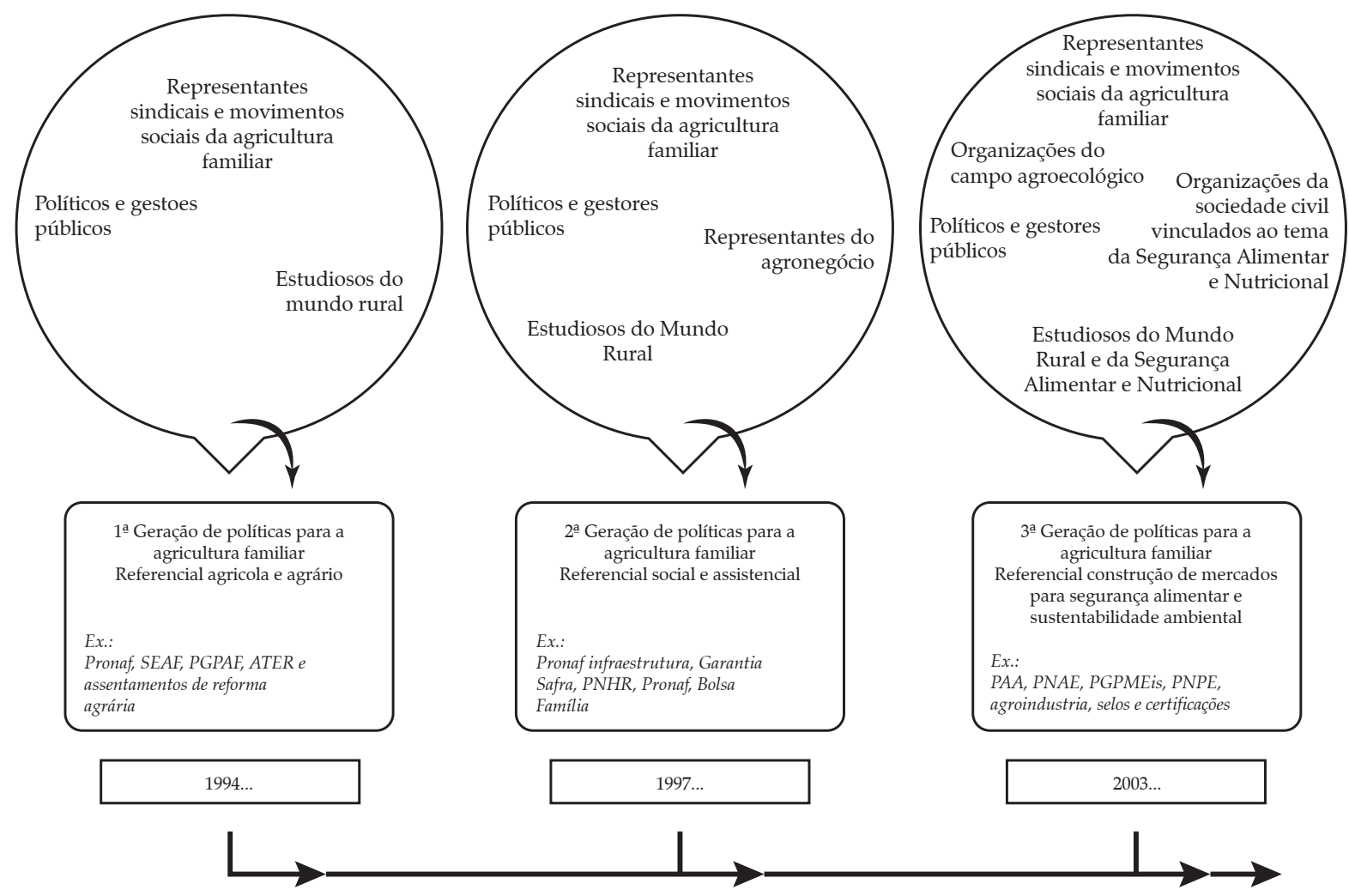

7 Dinâmica de emergência e institucionalização do referencial de política pública;

$\longrightarrow$ Presença do referencial na arena pública, ainda que ocilando em termos de intensidade de execução;

Principais grupos na construção de referencial.

Fonte: Construção dos autores.

\section{Segunda geração de} políticas para a agricultura familiar: a construção de um referencial social e assistencial

Conforme anunciado, na década de 1990 vigorou o referencial global do neoliberalismo, que ganhou repercussão principalmente nos governos Collor de Mello e Fernando Henrique Cardoso. Para além da desestruturação de instrumentos de políticas públicas importantes, como a extinção da Empresa Brasileira de Assistência Técnica e Extensão Rural (Embrater) em 1990, da liberalização dos mercados e da reti- rada do Estado na economia (com importantes repercussões na taxa de câmbio e na relação importação/exportação), este referencial global repercutiu nas políticas para a agricultura familiar. Compreendia-se que o Estado deveria "corrigir as falhas de mercado", notadamente atuando no combate à pobreza rural (BANCO MUNDIAL, 1994). Neste contexto, a partir de 1997-98, as políticas para a agricultura familiar aportaram para um novo referencial setorial focado em ações sociais e assistenciais, configurando, nos termos de Schneider, Shiki e Belik (2010), o início de uma segunda geração de políticas para a agricultura familiar. 
Esta mudança tem seu início no Governo FHC, com o Programa Comunidade Solidária, e se consolida no Governo Lula, por meio do Programa Fome Zero, no qual o Bolsa Família é um dos destaques. O Programa Comunidade Solidária propunha avançar na parceria Estadosociedade e contemplar ações relacionadas com a questão alimentar, a miséria, pobreza e inequidade. A proposta do "Comunidade Solidária" era conferir "selo de prioridade" a 16 programas governamentais em seis áreas de atuação: redução da mortalidade na infância, alimentação, apoio ao ensino fundamental e pré-escolar, habitação e saneamento, geração de ocupação e renda e qualificação profissional, e fortalecimento da agricultura familiar (BRASIL, COMUNIDADE SOLIDÁRIA, 1998). Buscava-se construir a integração e a convergência dessas ações em áreas geográficas (municípios) com maior concentração de pobreza (MALUF, 2007; TAKAGI, 2006; PELIANO, 2001). Com base neste referencial, delineado fundamentalmente a partir das ideias de políticos, gestores públicos e estudiosos vinculados ao ideário liberal, as políticas para a agricultura familiar se aproximaram das políticas sociais (MARQUES, 2004; VILELA, 1997; BANCO MUNDIAL, 1994).

Em relação à agricultura familiar, o primeiro passo nessa direção foi a criação da linha Infraestrutura e Serviços Municipais do Pronaf, que visava dar apoio a infraestruturas para os municípios com "a distribuição fundiária mais pulverizada, a menor taxa de urbanização e a mais baixa produtividade agrícola", ou seja, municípios mais periféricos e mais pobres, distanciando-se, segundo Abramovay e Veiga (1999), da proposta originalmente construída para este Programa9. As organizações da agricultura familiar temeram que a aproximação do

9. Cabe destacar que, no âmbito das políticas sociais para a agricultura familiar, uma ação pioneira foi a inclusão dos trabalhadores em regime de economia familiar no sistema de seguridade social pela Constituição Federal de 1988 (DELGADO, 2014). Esta medida antecede o próprio reconhecimento político da categoria agricultura familiar que iria ocorrer em meados da década de 1990, como visto na seção anterior.
Pronaf com o Programa Comunidade Solidária alterasse o programa como um todo, tornando-o um programa de assistência social. No III Grito da Terra Brasil (1996, p.13), as organizações da agricultura familiar assim se manifestaram a respeito: “O Pronaf não pode ser confundido com programas de assistência social, mas deve ser uma prioridade do Governo Federal pelo desenvolvimento da agricultura familiar, definida como a mais eficiente nos aspectos econômico e social". Conforme Marques (2004, p. 12), neste contexto, a Contag e a Secretaria de Desenvolvimento Rural do Maara, que gestaram o Pronaf, afastaram-se progressivamente do Programa Comunidade Solidária. "O distanciamento foi acompanhado pela recusa, por parte destas últimas, da associação de suas iniciativas com os propósitos que privilegiam, antes de tudo, os objetivos visando o combate à miséria em torno do apoio à agricultura familiar."

Todavia, logo após a institucionalização do Pronaf, as próprias organizações da agricultura familiar começaram a pautar a necessidade de o Pronaf atender a diversidade socioeconômica da agricultura familiar, culminando na criação de grupos e linhas direcionadas aos agricultores mais descapitalizados ou em situação de vulnerabilidade social, a exemplo da criação do "Pronafinho" em 1997 e do Grupo B ${ }^{10}$, em 1999. Havia a preocupação de que a continuidade das regras e normas inicialmente estabelecidas no Pronaf poderiam reproduzir desigualdades expressivas no interior da agricultura familiar (GRISA, 2012).

De 1998 até meados dos anos 2000, emergiu um conjunto de ações de transferência de renda que contemplaram a agricultura familiar (ainda que não exclusivamente), como o Bolsa Escola, Bolsa Alimentação e Auxílio Gás, que a partir de 2003 foram integradas ao Programa Bolsa Família. O Programa Fome Zero, criado no início

10. Visando ampliar a participação da diversidade da agricultura familiar no Pronaf, em 1999 teve inicío a criação de grupos no interior do Programa de acordo com o grau de capitalização dos agricultores familiares e de_beneficiários de programas de reforma agrária. O grupo $\mathrm{B}$ se refere aos agricultores em maior vulnerabilidade social e corresponde ao microcrédito produtivo rural. 
do Governo Lula, daria um novo impulso a estas ações, às políticas sociais e ao combate à pobreza rural (e urbana). Posteriormente, já no governo Dilma Roussef, estas ações foram retomadas e potencializadas com a criação do Plano Brasil Sem Miséria, seja com o incremento do Programa Bolsa Família, da criação do Brasil Carinhoso e do Programa Bolsa Verde, seja com ações que visam à inclusão socioprodutiva da população rural em pobreza extrema por meio da disponibilização de crédito de fomento a fundo perdido ( $\mathrm{R} \$ 2.400,00$ / família) para a aquisição de insumos e equipamentos, assistência técnica diferenciada para este público, e doação de sementes e tecnologias da Embrapa para iniciar os processos produtivos.

Dando sequência à criação de políticas diferenciadas para a agricultura familiar, agora orientadas pelo referencial setorial focado em políticas sociais e assistenciais, em 2002 foi estabelecido o Programa Garantia Safra, voltado ao segmento mais vulnerável desta categoria social, visando garantir renda aos agricultores localizados na região Nordeste do País, norte de Minas Gerais, Vale do Mucuri, Vale do Jequitinhonha e norte do Espírito Santo que sofrerem com a perda de safra por motivos de seca ou excesso de chuvas.

Em 2003, já no Governo Lula, foi criado o Programa de Habitação Rural (PNHR) com o fito de garantir subsídios financeiros para a aquisição de materiais para a construção ou conclusão/ reforma/ampliação de unidades habitacionais de agricultores familiares e trabalhadores que atendam aos critérios estabelecidos pelo Pronaf. Atualmente, o Programa Nacional de Habitação Rural faz parte do Programa Minha Casa, Minha Vida, criado em 2009, contribuindo para a melhoria de infraestruturas e para o bem-estar das famílias rurais.

Ainda em 2003, foi extinto o Pronaf Infraestrutura e Serviços Municipais que deu lugar ao Programa Desenvolvimento Sustentável de Territórios Rurais (Pronat), que buscava promover o desenvolvimento, infraestruturas e a gestão de territórios rurais. Os Territórios "despertavam" como um espaço intermediário entre os municípios e os estados, possibilitando a parti- cipação da sociedade civil vinculada à agricultura familiar nas decisões de desenvolvimento. Ainda que o Pronat não tenha emergido explicitamente com um viés para combater a pobreza rural, na delimitação dos territórios foram priorizados, dentre outros critérios, contextos com maior concentração do público prioritário do MDA (agricultores familiares, assentados da reforma agrária e agricultores beneficiários do reordenamento agrário) - portanto, com maior intensidade de demanda social - e com Índices de Desenvolvimento Humano reduzido, de modo a priorizar os municípios com menores condições de desenvolvimento (DELGADO e LEITE, 2011; ECHEVERRI, 2009).

Em 2008, esta perspectiva de atuação via territórios ganhou um novo impulso com a criação do Programa Territórios da Cidadania (PTC) que visava articular e potencializar as ações de um conjunto de políticas públicas em alguns territórios economicamente mais fragilizados. A prioridade era atender territórios que apresentavam baixo acesso a serviços básicos, índices de estagnação na geração de renda e carência de políticas integradas e sustentáveis para autonomia econômica de médio prazo. A relação entre políticas territoriais e pobreza ganhava contornos mais evidentes no PTC. Ainda que não exclusivos à agricultura familiar, o Pronat e o PTC beneficiaram sobremaneira a categoria social.

No decorrer dos anos, este referencial de política pública orientado pelo social e socioassistencial passou a apresentar certas ambiguidades referentes à sua origem e aos seus propósitos. Por um lado, representantes da agricultura familiar, gestores públicos e estudiosos do mundo rural passam a reivindicar um "olhar" mais atento do Estado aos grupos vulneráveis da categoria social e do mundo rural e reivindicam políticas sociais para estes, seja no sentido de contribuir e garantir a sua reprodução social, seja com vistas a dar condições para que estes atores conseguissem minimamente alterar suas condições sociais e econômicas e passassem a interagir nos mercados agrícolas e de trabalho (BIANCHINI, 2010; MATTEI, 2006; BRASIL, MINISTÉRIO DA AGRICULTURA E 
DO ABASTECIMENTO, 1998; GRITO DA TERRA BRASIL, 1998). A criação do Pronaf B, do Programa Garantia Safra, do PNHR, das políticas territoriais e do Programa de Fomento às Atividades Produtivas Rurais incluído no Plano Brasil Sem Miséria são exemplos neste sentido.

Por outro lado, este mesmo referencial passou a ser reivindicado por representantes do setor denominado politicamente como agronegócio, promovido por estudiosos do mundo rural e incorporado por segmentos da gestão pública (NAVARRO e CAMPOS, 2013; BUAINAIN e GARCIA, 2013; CNA, 2010; ALVES e ROCHA, 2010). Elucidando esta perspectiva, citam-se as interpretações de Alves e Rocha (2010). Segundo estes autores, a produção agropecuária nacional está concentrada em 8,19\% dos estabelecimentos (423.689) que atingiram um valor equivalente a $84,89 \%$ da produção dos 5.175 .489 de estabelecimentos. Além destes, há quase um milhão de estabelecimentos que "têm condições de melhorar sua renda na agricultura, mas carecem de ajuda no que diz respeito à extensão rural, crédito de custeio e investimentos, compra da produção quando os preços despencam etc.". "Restam 3.775.826 estabelecimentos, cujo valor da produção é de R\$128,13 por mês. Na agricultura, simplesmente não há solução para o problema de pobreza destes. Forte dose de política social, de caráter assistencialista faz necessária para manter as famílias a eles vinculadas nos campos" (ALVES e ROCHA, 2010, p. 288). Nesta perspectiva agrícola-centrada, grande parte da agricultura familiar - ou da "pequena produção", como mencionam - deve ser objeto de políticas sociais e de outras políticas que incrementem as possibilidades de renda não agrícola, direcionando as políticas agrícolas apenas para os segmentos economicamente mais estruturados do agronegócio.

A geração de políticas com enfoque em ações de cunho social e assistencial tem sido indicada por analistas e mesmo por gestores públicos como as responsáveis pela redução da pobreza e da desigualdade no meio rural. Há inúmeras evidências estatísticas que dão suporte a estes resultados. Mas o que nos interessa salientar é que estas políticas passaram a ser especialmente importantes nas regiões rurais do País, como a região do semiárido nordestino. Neste sentido, nem sempre de forma planejada e deliberadamente intencional, as políticas sociais e assistências acabaram tendo repercussões sobre o desenvolvimento rural sob um viés que não é da inclusão produtiva ou pela ativação do mercado de trabalho. Nas últimas duas décadas, as áreas rurais mais empobrecidas do Brasil conheceram melhorias inegáveis em seus indicadores convencionais de desenvolvimento (incremento de renda, por exemplo) que, talvez, não teriam sido alcançadas apenas por meio das ações agrícolas e agrárias que analisamos na primeira geração de políticas.

\section{Terceira geração de políticas para a agricultura familiar: a construção de um referencial pautado pela construção de mercados para a segurança alimentar e a sustentabilidade ambiental}

Os anos 2000 se iniciam sob o efeito de uma mudança política importante, que decorre das eleições presidenciais de 2002 e da assunção de Luiz Inácio Lula da Silva à Presidência da República. De um governo identificado com os princípios do referencial global do neoliberalismo e lastreado por uma aliança política com os setores mais conservadores da política nacional, passou-se a um governo eleito com o apoio e participação de vários partidos e movimentos sociais situados mais à esquerda do espectro político sem, no entanto, deixar de contemplar ideias e interesses de grupos representantes da burguesia bancária, industrial e agrícola nacional (MIELITZ, 2011). Neste contexto, segundo Mielitz (2011, p. 239), "rupturas radicais com o modelo do passado [...] acabaram por não acontecer" e a manutenção da estabilidade econômica com um baixo nível de inflação tornou-se uma meta "sagrada" que subordinava outras questões. Não obstante, 
importantes alterações ocorreram nas relações e no papel do Estado e da sociedade civil, especialmente no que se refere ao direcionamento das políticas públicas, na relação com os movimentos sociais e com a sociedade civil. Atores até então marginais nas arenas públicas tornaram-se dominantes (caso de políticos vinculados ao Partido dos Trabalhadores) e abriram oportunidades para a institucionalização de "novas" ideias e reivindicações de políticos, estudiosos, movimentos sociais e de organizações da sociedade civil, dentre estes principalmente daqueles atuantes no tema da segurança alimentar e nutricional (e também, em grande medida, vinculados ao campo agroecológico).

Estes atores vinham propondo e disputando as políticas públicas desde o início dos anos 1990; no entanto, é apenas com a mudança política em 2002 que os mesmos conseguiram pautar a construção e a institucionalização das políticas públicas para a agricultura familiar com base em um novo referencial orientado pela construção de mercados para a segurança alimentar e a sustentabilidade. Referimo-nos especialmente aos atores vinculados ao "Governo Paralelo", que propôs a Política Nacional de Segurança Alimentar (PNSA) (não implementada) em 1991; à mobilização "Ação da Cidadania Contra a Fome, a Miséria e pela Vida", liderada pelo sociólogo Herbert de Souza (o Betinho), e à respectiva "Campanha Nacional de Combate à Fome" em 1993; e ao Conselho Nacional de Segurança Alimentar e Nutricional (Consea) estabelecido em 199311. Estes atores foram importantes para colocar o tema da fome em pauta no início dos anos 1990 e para defender políticas de segurança alimentar e nutricional, em que, atrelada a esta noção, ao

11. O Consea foi estabelecido inicialmente em 1993, no governo de Itamar Franco, no bojo de iniciativas que buscavam reduzir a fome e construir uma política de segurança alimentar e nutricional para o País. No entanto, este "primeiro" Consea teve "vida curta", sendo extinto no início da gestão de Fernando Henrique Cardoso, em 1995. O Consea foi restabelecido em 2003, constituindo-se como um importante espaço para representantes da sociedade civil e atores governamentais discutirem, construírem propostas e monitorarem iniciativas de promoção da segurança alimentar e nutricional no País. mesmo tempo reivindicava-se a agricultura familiar como meio de promover o acesso aos alimentos e um sistema agroalimentar mais equitativo. Com o início do Governo FHC e o consequente arrefecimento do tema da segurança alimentar e nutricional (substituído pelo Programa Comunidade Solidária), estes atores encontraram limitações políticas e institucionais para atuarem na construção de políticas públicas,

Quando o Presidente Lula assumiu, os temas da fome e da segurança alimentar e nutricional ganharam um novo ímpeto e estes atores encontraram possibilidades para institucionalizarem suas ideias. O Consea foi restabelecido e foi criado o Ministério Extraordinário de Segurança Alimentar e Combate à Fome (MESA), tornando-se ministro o professor José Graziano da Silva, um importante intelectual que teve papel decisivo na formulação e implementação do projeto Fome Zero, o que, segundo Menezes (2010, p. 247), "representou a culminância de todo um processo anterior de formulações e práticas na luta contra a fome e pela segurança alimentar e nutricional no Brasil experimentadas por governos (nos níveis municipal e estadual) e organizações sociais". O Projeto Fome Zero partiu da premissa do direito humano à alimentação e do diagnóstico de que este não estava sendo efetivado em razão da insuficiência da demanda, da incompatibilidade dos preços dos alimentos com o poder aquisitivo da maioria da população e da exclusão da população pobre do mercado. Para alterar este cenário, foi proposto um conjunto de políticas estruturais que visavam melhorias na renda e o aumento da oferta de alimentos básicos, ou seja, era preciso mudanças na "ponta" da produção, conferindo prioridade à agricultura familiar, e na "ponta" do consumo, de preferência articulando-as.

Resgatando experiências de alguns municípios e estados brasileiros, o Projeto Fome Zero ressaltava o potencial do mercado institucional (alimentação escolar, hospitais, presídios, distribuição de cestas básicas etc.) no fortalecimento da agricultura familiar (criação de canais de comercialização e geração de renda), na dinamização da 
economia dos municípios e das regiões, no atendimento às necessidades alimentares de "uma parcela vulnerável e numericamente expressiva da população" (mormente, as crianças em idade escolar) e na introdução de "elementos de diversidade regional em cardápios com importância não desprezível na formação de hábitos alimentares" (INSTITUTO CIDADANIA, 2001, p. 39). Estimava-se que uma parte importante do orçamento público era destinada à compra de alimentos para várias finalidades e esta demanda institucional deveria ser canalizada para a agricultura familiar. Estas ideias culminaram na criação do Programa de Aquisição de Alimentos (PAA) e desencadearam uma efervescência em torno dos mercados institucionais, seja do ponto de vista da segurança alimentar e nutricional - sendo a alimentação escolar um elemento central - seja com um viés para as preocupações ambientais, com a produção de bicombustíveis (neste caso, de forma controversa). De acordo com Schneider, Shiki e Belik (2010), neste processo estaria emergindo uma terceira geração de políticas públicas para a agricultura familiar. A criação do Programa de Aquisição de Alimentos, PAA, foi elemento fundamental neste processo, abrindo uma "janela de oportunidades" e gerando aprendizados para a construção de novas ações.

O PAA foi criado em 2003 visando articular a compra de produtos da agricultura familiar com ações de segurança alimentar (distribuição de alimentos) para a população em vulnerabilidade social. Embora concebido como uma ação estruturante no Programa Fome Zero, o PAA apresentou certa "timidez" em seus anos iniciais, dadas certas mudanças políticas (extinção do Mesa) e o fato de ser compreendido a partir da lógica de "projetos pilotos" pelas organizações da agricultura familiar (GRISA, 2012; MULLER, 2007). Com a expansão do Programa, a exposição de seus resultados para as dinâmicas locais e para o fortalecimento das organizações da agricultura familiar, e o crescente debate no Brasil neste período sobre construção social dos mercados (NIEDERLE, 2011; ABRAMOVAY, 2009; WILKINSON, 2008; MALUF, 2004), o Programa ganhou importante projeção nacional e internacional, servindo de exemplo a ser "replicado" ou "exportado" para outros países.

Após romper com importantes barreiras institucionais (como a Lei de Licitações), o PAA desencadeou uma nova trajetória para os mercados institucionais para a agricultura familiar, fortalecida em 2009 com mudança no Programa Nacional de Alimentação Escolar (PNAE) e a criação da Lei n. 11.947 que determinou que no mínimo 30\% dos recursos federais para a alimentação escolar sejam destinados para a aquisição de alimentos da categoria social. Mais recentemente, em 2012, foi estabelecida mais uma modalidade ao PAA, que amplia as possibilidades de mercados. Trata-se da Compra Institucional que permite aos estados, municípios e órgãos federais da administração direta e indireta adquirir alimentos da agricultura familiar por meio de chamadas públicas, com seus próprios recursos financeiros, com dispensa de licitação. Em termos práticos, isto significa o acesso a mercados alimentares demandados por hospitais, quartéis, presídios, restaurantes universitários, refeitórios de creches e escolas filantrópicas, entre outros.

Estas iniciativas têm estimulado governos estaduais a criar seus próprios mecanismos de compras públicas e têm estimulado as organizações da agricultura familiar a demandarem e construírem novos mercados públicos e privados. Cabe ressaltar que estas ações (PAA e PNAE) têm contribuído para a valorização da produção local/ regional, ecológica/orgânica e têm ressignificado os produtos da agricultura familiar, promovendo novos atributos de qualidade aos mesmos, associados, por exemplo, à justiça social, equidade, artesanalidade, cultura, tradição etc.

Em 2004, emergiu também o Programa Nacional de Produção e Uso do Biodiesel (PNPB), visando estimular a produção e compra de oleaginosas da agricultura familiar. Além de promover a produção de oleaginosas geradoras de biodiesel via política agrícola (crédito rural, Ater, seguro agrícola), o Programa instituiu o selo "combustível social" concedido pelo MDA ao produtor de biodiesel que adquirir matéria-prima e assegurar assistência técnica aos agricultores familiares, 
beneficiando-se, em contrapartida, de financiamentos e incentivos comerciais e fiscais. Ainda que, muitas vezes controversa do ponto vista da segurança alimentar e da questão ambiental (sobretudo pelo fato de concentrar-se no uso da soja como matéria-prima), a produção de biodiesel incrementou os mercados para a agricultura familiar e suas organizações (FLEXOR e KATO, 2014).

Complementando as ações de comercialização, é importante ressaltar também a criação da Política de Garantiria de Preços Mínimos (PGPM) para os Produtos da Sociobiodiversidade (PGPM Bio) em 2008, garantindo um atendimento específico para os extrativistas no interior da PGPM, instituída ainda em 1945. Por meio da Lei n. 11.775 de 2008, estabeleceu-se a modalidade de Subvenção Direta, que assegura ao extrativista o recebimento de um bônus caso efetue a venda de seu produto por preço inferior àquele fixado pelo Governo Federal. Diferente do PAA e do PNAE, não se trata aqui de aquisições pelo poder público, mas de uma complementação financeira repassada diretamente aos extrativistas ou suas organizações até atingir o preço mínimo de comercialização. Embora ainda seja pouco expressiva (50 mil extrativistas beneficiários e R $\$ 16$ milhões aplicados desde 2009 - BRASIL, CONAB, 2014), a modalidade auxilia na preservação dos recursos naturais e na reprodução social dos extrativistas.

Concomitante a estas iniciativas foram incrementadas ações direcionadas à agregação de valor, como o apoio às agroindústrias (promoção, infraestruturas, crédito etc.), os aprimoramentos nos instrumentos de fiscalização da sanidade agropecuária (Sistema de Inspeção Municipal, Estadual, Federal e Sistema Unificado de Atenção à Sanidade Agropecuária), a criação de selos de diferenciação (Selo da Identificação da Participação da Agricultura Familiar, Selo Quilombos do Brasil, Indicações Geográficas) e a ampliação dos mecanismos de certificação, com destaque para a certificação orgânica, também viabilizada por meio de sistemas participativos de garantia.

Em seu conjunto, esta terceira geração de políticas públicas contou com a participação pro- eminente de atores vinculados ao debate da segurança alimentar e nutricional (Consea), assim como organizações agroecológicas, entidades da agricultura familiar, gestores públicos e estudiosos da agricultura familiar, segurança e abastecimento alimentar. A participação destes "novos" atores e ideias nas arenas públicas provocou certo redirecionamento das políticas para a construção de mercados vinculados à segurança alimentar e à sustentabilidade, sem deixar de ser igualmente importante a atuação destes atores para a afirmação política da categoria social e edificação das demais políticas públicas citadas.

Retomando a análise da relação entre Estado e sociedade civil, cabe destacar algumas mudanças observadas na segunda e na terceira geração de políticas públicas para a agricultura familiar. Estas mudanças tiveram origem ainda na década de 1990, a partir de uma certa "confluência perversa" entre o projeto neoliberal e o projeto participativo/democratizante: "A perversidade está colocada no fato de que, apontando para direções opostas e até antagônicas, ambos os projetos requerem uma sociedade civil ativa e propositiva" (DAGNINO, 2002, p. 289). Descentralização, sociedade civil e participação faziam parte do repertório discursivo de ambos os projetos. Nesta confluência, observamos que os movimentos sociais e sindicais da agricultura familiar de uma postura propositiva passaram a ser parceiros na execução das políticas públicas. Desde a segunda metade da década de 1990, um número progressivo de políticas públicas e programas passou a envolver, nas fases de formulação e de operacionalização, parcerias com organizações da sociedade civil, ou o que poderíamos denominar de cogestão nas políticas públicas.

De acordo com Silva e Schmitt (2012, p. 2), "a criação de novas figuras jurídicas, como as Organizações Sociais (OSs-Lei n. 9.637/1998) e as Organizações da Sociedade Civil de Interesse Público (OSCIPs - Lei n. 9.790/1999), assim como o crescente volume de recursos públicos transferidos para tais organizações, são indicativos da importância deste processo. "No campo das políticas de desenvolvimento rural, são vários 
os exemplos de ações que aproximam Estado e organizações sociais na execução dos programas, como o Projeto Lumiar (1997), o Programa Um Milhão de Cisternas (2003), o PAA, o PNHR (2003), o Programa Nacional de Alimentação Escolar (PNAE) e a Política Nacional de Assistência Técnica e Extensão Rural (2003) (BOLTER, 2013; DIESEL e NEUMANN, 2012; SILVA e SCHMITT, 2012).

Assim, se na década de 1980 as políticas públicas eram um objeto de reivindicação das organizações, na década de 1990 e, especialmente, na década de 2000, a implementação de políticas públicas se torna crescentemente um campo de atuação para tais organizações (e, em alguns casos, se torna o campo prioritário de atuação) (SILVA e SCHMITT, 2012, p. 23).

É importante ressaltar que esta permeabilidade do Estado não é recente. Cardoso (1970) observou, já no primeiro Governo Vargas e também durante o regime militar, que a organização do Estado ocorria com base em "anéis burocráticos", ou seja, círculos que conectavam e representavam ideias e interesses dos militares, da burocracia governamental, de empresários (nacionais e internacionais), da alta classe média, entre outros (ROMANO, 2009). Esses anéis poderiam ser formados em torno de interesses específicos (não apenas econômicos) por um tempo indeterminado, até que o problema fosse solucionado; por exemplo, a articulação em torno de uma política pública específica, uma decisão governamental importante etc. Tratava-se de um Estado regulador, pouco permeável às demandas da sociedade civil ou, em outras palavras, de um Estado autoritário em que apenas os grupos de interesse que ofereciam suporte ao grupo político no poder dialogavam com os burocratas responsáveis pela formulação das políticas públicas. De forma similar, Marques (1999) evidenciou fronteiras difusas entre o público e o privado na política de saneamento básico no Rio de Janeiro entre 1975 e 1996. Segundo o autor, empresas de portes distintos utilizavam diferentes estratégias para obter informações e vencer licitações, desta- cando, nestas situações, a utilização de relações pessoais e institucionais no interior da rede.

No entanto, diferente destas situações, um elemento importante da permeabilidade em anos recentes da gestão pública consiste na proximidade entre Estado e organizações da sociedade civil na formulação e na cogestão das políticas públicas $^{12}$. Diferente de perspectivas dicotômicas que aludiam para a autonomia ou à institucionalização das relações entre Estado e organizações da sociedade civil, passa-se a enfatizar uma abordagem relacional, cujas implicações deste processo para o Estado, para as organizações sociais e para as políticas públicas ainda precisam ser melhor investigadas (BOLTER, 2013; SILVA e SCHMITT, 2012) ${ }^{13}$.

\section{Considerações finais}

As últimas duas décadas foram pródigas em relação à criação e execução de um amplo espectro de políticas públicas direcionadas para a agricultura familiar, que se iniciaram em meados dos anos 1990. Neste artigo, procuramos analisar este conjunto de políticas e identificamos três gerações, que a nosso ver podem ser agregadas e sistematizadas em três referenciais de política pública: um primeiro que foca no viés agrícola e agrário,

12. Recentemente (23 de maio de 2014), a presidente Dilma assinou um decreto que estabelece regras e diretrizes para o funcionamento no País de Organizações Não Governamentais (ONGs). Em seu discurso, a presidente fez a seguinte afirmação: “Com elas [novas regras], nós vamos garantir uma coisa importantíssima, que é mais clareza e mais segurança jurídica para os gestores das ONGs e vamos reconhecer algo que é fundamental. Vamos reconhecer o papel das ONGs na execução de políticas governamentais de uma forma explícita".

13. Cabe destacar igualmente que, no governo de Dilma, alguns eventos "colocaram em questão" a credibilidade pública da atuação de organização da sociedade civil na implementação das políticas públicas. O caso mais recente de possíveis irregularidades na execução do PAA no Paraná e a construção de uma "retórica da intransigência" (TRICHES e GRISA, 2014) são elucidativos neste sentido. Ademais, o próprio governo federal, nas últimas três gestões, vem direcionando suas ações para o fortalecimento do pacto federativo. Estes elementos podem desencadear novos processos e relações entre Estado e sociedade civil na construção e execução das políticas públicas. 
um segundo direcionado para políticas sociais e assistenciais, e um terceiro, orientado pela construção de mercados para a segurança alimentar e nutricional e para a sustentabilidade.

A partir de uma análise cronológica, procuramos mostrar que estes referenciais emergiram em contextos e períodos específicos, subsidiados por reflexões acadêmicas e oportunizados por mudanças políticas, eventos sociais importantes (mobilizações sociais, conflitos agrários) e pela entrada de novos atores e ideias nas arenas públicas. Após a emergência destes referenciais, um olhar retrospectivo permite afirmar que estas gerações resultaram em certa dependência de caminho ou "efeitos de feedback institucionais" e, como as demandas perpetradas pelos atores sociais não foram ainda inteiramente atendidas e as mobilizações sociais persistem, estas gerações de políticas foram se ampliando e novos instrumentos e estratégias de ação foram se agregando.

Malgrado tenham surgido em momentos críticos distintos e diferentes atores ou organizações tenham sido seus proponentes, estas três gerações ou referenciais de política pública para a agricultura familiar convivem atualmente nas arenas públicas. Entretanto, não se trata de uma convivência pacífica e sem conflitos, uma vez que há áreas de maior ou menor fricção que podem ser acentuadas ou arrefecidas em momentos distintos, dependendo das disputas e dos jogos de poder em questão, tais como eleições, negociações na gestão pública, conjuntura política, pressão dos movimentos sociais e sindicais da agricultura familiar, influência da "coalizão de interesses" do agronegócio etc. A opção ou as condições favoráveis para que haja o fortalecimento das dimensões agrícola e agrária (esta última minimizada no período recente), ou das políticas sociais e assistenciais, ou da construção de novas inserções mercantis (ou ainda os três referenciais em conjunto) fazem parte das disputas, lutas e interpretações sobre o lugar e o papel da agricultura familiar na sociedade brasileira e no desenvolvimento rural.

A análise empreendida neste artigo também nos permite afirmar que os repertórios da ação coletiva de atores sociais podem variar ao longo de uma trajetória temporal. Protesto, proposição e cogestão fazem parte das formas de ação coletiva dos movimentos sociais e sindicais da agricultura familiar na contemporaneidade, ainda que com diferentes ardores, estratégias e "formatações" de outrora. Os movimentos sociais e sindicais da agricultura continuam acionando estratégias de protesto e de reivindicação (a exemplo dos Gritos da Terra, da Marcha das Margaridas, do Abril Vermelho, das ocupações de prédios públicos, das Jornadas de Luta da Agricultura Familiar etc.), se instrumentalizam cada vez mais para propor formatos institucionais e políticos para as políticas públicas, e reivindicam a cogestão e a execução partilhada das políticas públicas, seja visando aproximá-las e adaptá-las às distintas realidades sociais, seja para o empoderamento das próprias organizações sociais.

Em um contexto em que o processo de transição democrática parece ter avançado, os atores da sociedade civil passaram a ocupar um espaço que, por um lado, lhes confere maior legitimidade e reconhecimento, mas, por outro, cria novos desafios relativos à relação mais institucionalizada com o Estado (cogestão das políticas públicas), e à governança, gestão e administração de suas organizações. Estas questões e as repercussões deste processo na sociedade civil organizada precisariam ser aprofundadas pelos estudos e pesquisas rurais, como também seria necessário mais reflexão sobre os seus desdobramentos na estrutura e na governança do próprio Estado. Quais os limites e/ou as condições e possibilidades de que, em tempos vindouros, as organizações da sociedade civil sejam capazes de confrontar as mudanças conjunturais que venham a surgir (mudanças climáticas, entre outras) e mesmo retomar o enfrentamento a algumas amarras estruturais (restrições ao acesso à terra e melhoria da infraestrutura no meio rural, apenas dois exemplos), com a mesma criatividade e capacidade de inovação que as gerações de políticas do passado recente demonstraram? Que mudanças ocorrem nas políticas públicas e em seus resultados quando elas são executadas pela sociedade civil organizada? Quais as repercussões 
da cogestão das políticas públicas na governança e na estrutura administrativa (entes federados) do Estado brasileiro? Quais são e de que forma operam os mecanismos de controle social? Estas são algumas das questões que chamam a atenção para estudos e pesquisas rurais no próximo período.

\section{Referências bibliográficas}

ABRAMOVAY, R. Paradigmas do capitalismo agrário em questão. Campinas (SP): Editora Hucitec/Editora da UNICAMP, 1992.

. Anticapitalismo e inserção social dos mercados. Tempo social, v. 21, n. 1, p. 65-77, 2009.

e VEIGA, J.E. Novas instituições para o desenvolvimento rural: o caso do Programa Nacional de Fortalecimento da Agricultura Familiar (PRONAF). Brasília/DF: IPEA, 1999. (Texto para Discussão, 641).

. e MORELLO, T. F. A democracia na raiz das novas dinâmicas rurais brasileiras. In: International Conference Dynamics of Rural Transformations in Emerging Economies, April 14-16, 2010, New Delhi, India.

ALVES, E. e ROCHA, D. P. Ganhar tempo é possível?. In: GASQUES, J. G., VIEIRA FILHO, J. E.R. e NAVARRO, Z. A agricultura brasileira: desempenho recente, desafios e perspectivas. Brasília: Ipea/Mapa, 2010.

BANCO MUNDIAL. Brazil: the management of agriculture, rural development and natural resources. Report no. 11783-BR, v. I, 1994.

BIANCHINI, V. O Programa Nacional de Fortalecimento da Agricultura Familiar - PRONAF e a sustentabilidade da agricultura no Vale do Ribeira - Paraná. Tese (Doutorado em Meio Ambiente e Desenvolvimento) - Programa de Pós-Graduação em Meio Ambiente e Desenvolvimento (MADE/UFPR). Curitiba (PR), 2010.

BIELSCHOWSKY, R. Vigencia de los aportes de Celso Furtado al estructuralismo. Revista de La CEPAL, 88, p. 07-15, 2006.

Cinquenta anos de pensamento na CEPAL: uma resenha. In: BIELSCHOWSKY, R. (Org.) Cinqüenta anos de pensamento na CEPAL. v. 1. Rio de Janeiro (RJ)/ São Paulo (SP): Editora Record, 2000. p. 13-68.

BOLTER, J. A. G. Interfaces e cogestão nas politicas para agricultura familiar: uma análise do Programa Nacional de Habitação Rural. Tese (Tese de Doutorado em Ciências Sociais) - Programa de Pós-Graduação em Desenvolvimento Rural/UFRGS, 2013.
BRASIL, COMPANHIA NACIONAL DE ABASTECIMENTO. PGPM Bio beneficia cerca de 50 mil extrativistas em 5 anos. 2014. Disponível em: <http:// www.conab.gov.br/imprensa-noticia.php?id=33512>. Acesso em: 19 ago. 2014.

BRASIL, COMUNIDADE SOLIDARIA. Comunidade solidária: três anos de trabalho, 1998.

BRASIL, Ministério da Agricultura e do Abastecimento. PRONAF: construindo as instituições do desenvolvimento rural. Brasília (DF): Secretaria de Desenvolvimento Rural/MAARA, 1998.

BRASIL, Ministério da Agricultura, do Abastecimento e da Reforma Agrária (MAARA)/Confederação Nacional dos Trabalhadores na Agricultura (CONTAG). Propostase recomendações de política agrícola diferenciada para o pequeno produtor rural. Brasília (DF): MAARA/CONTAG, 1994.

BUAINAIN, A. M. e GARCIA, J. R. Desenvolvimento rural do semiárido brasileiro: transformações recentes, desafios e perspectivas. Confins (Paris), v. 1, p. 1, 2013.

CARDOSO, F. H. Aspectos políticos do planejamento. In: MINDLIN LAFER, B. Planejamento no Brasil. São Paulo (SP): Editora Perspectiva, 1970.

CASTRO, A. C. Ciência e tecnologia para a agricultura: uma análise dos planos de desenvolvimento. Cadernos de difusão de tecnologia, v. 1, n. 3, p. 299-482, 1984.

CENTRAL ÚNICA DOS TRABALHADORES (CUT). Proposta para um projeto de lei agrícola. São Paulo (SP): CUT, 1991.

\section{9.}

. Cartilha de politica agrícola. São Paulo (SP): CUT,

COELHO, C. N. 70 anos de política agrícola no Brasil (1931-2001). Revista de política agrícola, ano x, n. 3, p. 3-58, 2001.

CONFEDERAÇÃO NACIONAL DA AGRICULTURA. Quem produz o que no campo: quanto e onde II: censo agropecuário 2006: resultados: Brasil e regiões. Brasília: CNA, 2010.

CONFEDERAÇÃO NACIONAL DOS TRABALHADORES NA AGRICULTURA (CONTAG). Anais - II Congresso nacional dos trabalhadores rurais. Brasília (DF): CONTAG, 1973.

. Anais - 3ํ․ Congresso nacional dos trabalhadores rurais. Brasília (DF): CONTAG, 1979a.

. O trabalhador rural. Boletim periódico, n. especial, ano $11,1979 \mathrm{~b}$.

Projeto Nacional de Política Agrícola. Brasília (DF): CONTAG, 1988. 
- Proposta do movimento sindical de trabalhadores rurais para as leis agrária e agrícola. Brasília (DF): CONTAG, 1989.

DAGNINO, E. Sociedade civil, espaços públicos e a construção democrática no Brasil: limites e possibilidades. In: DAGNINO, E. Sociedade civil e espaços públicos no Brasil. São Paulo (SP): Paz e Terra, 2002, p. 279-302.

DATALUTA, Relatório 2012. DataLuta, 2013.

DELGADO, G. C. Agricultura familiar e política agrícola no Brasil: situação atual e perspectivas. Reforma agrária, v. 24, n. 3, p. 5-35, set./dez. 1994.

. O setor de subsistência na economia brasileira: gênese histórica e formas de reprodução. In: JACCOUD, L. (Org.). Questão social e políticas sociais no Brasil contemporâneo. Brasília (DF): IPEA, 2005, p. 19-50. (mimeo).

Previdência social e desenvolvimento rural. 2014.

DELGADO, N. G. A agricultura nos planos de desenvolvimento do governo federal: do Plano Trienal ao III PND. In: BENETTI, M.D. e FRANTZ, T.R. Desenvolvimento e crise do cooperativismo empresarial do Rio Grande do Sul, 1957-1984. Porto Alegre (RS): Fundação de Economia e Estatística, 1988, p. 35-111.

. Política econômica, ajuste externo e agricultura. In: LEITE, S. Políticas públicas e agricultura no Brasil. Porto Alegre (RS): Editora da UFRGS, 2001, p. 15-52.

O papel do rural no desenvolvimento nacional: da modernização conservadora dos anos 1970 ao Governo Lula. In: DELGADO, N. G. Brasil rural em debate: coletânea de artigos. Brasília (DF): CONDRAF/ NEAD, 2010, p. 28-78.

DELGADO, N.G. e LEITE, S.P. Gestão social e novas institucionalidades no âmbito da política de desenvolvimento territorial.In:DELGADO,N.G. eLEITE, S. P. (Orgs.). Políticas públicas, atores sociais e desenvolvimento territorial no Brasil. Brasília, IICA. (Série Desenvolvimento Rural Sustentável, vol. 14), 2011, p. 89-130.

DIAS, G.L.S. e AMARAL, C. Mudanças estruturais na agricultura brasileira 1980-98. In: Baumann, Renato (org). Brasil: uma década em transição. Rio de Janeiro, Editora Campus (co-edição com a Cepal), 2000.

DIESEL, V. e NEUMANN, P. S. Extensão Rural no Contexto do Pluralismo Institucional: Reflexões a partir dos serviços de Ates aos assentamentos da reforma agrária no RS. 1. ed. Ijui: Editora UNIJUI, 2012..

ECHEVERRI, R. Identidade e território no Brasil. Brasília: IICA, 2009.
FAVARETO, A. Agricultores, trabalhadores: os trinta anos do novo sindicalismo rural no Brasil. Revista brasileira de ciências sociais, v. 21, n. 62, p. 27-45, 2006.

FERNANDES, B.M. A reforma agrária que o governo Lula fez e a que pode ser feita. In: SADER, E. 10 anos de governos pós-liberais no Brasil: Lula e Dilma. São Paulo (SP): Boitempo; Rio de Janeiro (RJ): Flacso Brasil, 2013, p. 191-206.

FLEXOR, G. e KATO, K. Políticas de Promoção dos Biocombustíveis e Agricultura Familiar: o que sugerem as recentes experiências internacionais? 2014 (mimeo).

FOUILLEUX, È. Analisar a mudança: políticas públicas e debates num sistema em diferentes níveis de governança. Estudos sociedade e agricultura, v. 19, n. 1, p. $88-125,2011$.

La politique agricole commune et ses réformes: une politique à l'épreuve de la globalisation. Paris: L'Harmattan, 2003.

GONÇALVES NETO, W. Estado e agricultura no Brasil: política agrícola e modernização econômica brasileira, 1960-1980. São Paulo (SP): Hucitec, 1997.

GRAZIANO DA SILVA, J. Tecnologia e agricultura familiar. Porto Alegre (RS): Editora da UFRGS, 1999.

GRITO DA TERRA BRASIL. Pauta de reivindicações do grito da terra Brasil/96. Brasília (DF): CUT, CONTAG, 1996.

. Grito da terra Brasil 1998. Pauta de reivindicações. Brasília (DF): 1998.

GRISA, C. Políticas públicas para a agricultura familiar no Brasil: produção e institucionalização das ideias. Tese (Doutorado em Ciências Sociais) - Programa de Pósgraduação de Ciências Sociais em Desenvolvimento, Agricultura e Sociedade/UFRRJ, 2012.

GRISA, C., WESZ JR., V.J. e BUCHWEITZ, V.D. Revisitando o Pronaf: velhos questionamentos, novas interpretações. Revista de Economia e Sociologia Rural, v.52, n. 2, 2014.

GUANZIROLI, C.E. PRONAF dez anos depois: resultados e perspectivas para o desenvolvimento rural. Revista de economia e sociologia rural, v. 45, n. 2, p. 301-328, 2007.

GUEDES PINTO, L.C. Notas sobre a política de crédito rural. In: Reunião da Sociedade Brasileira para o Progresso da Ciência, 3, 1978, Anais... São Paulo (SP): SBPC, 1978.

HALL, P. A. The role of interests, institutions and ideas in the comparative political economy of the industrialized nations. In: LICHBACH, M. I. e ZUCKERMAN, A. S. 
Comparative politics: rationality, culture and structure. Cambrigde University Press, 1997, p. 174-207.

INSTITUTO CIDADANIA. Projeto Fome Zero: uma proposta de política de segurança alimentar para o Brasil. 2001.

IPEA - INSTITUTO DE PESQUISA E ECONOMIA APLICADA. Capítulo 7. Desenvolvimento Rural. In: IPEA. Políticas sociais: acompanhamento e análise, n. 20, 2012.

JOBERT, B. Introduction: le retour du politique. In: JOBERT, B. Le tournant neoliberal en Europe: idées et recettes dans les pratiques gouvernementales. Paris: L'Harmattan, 1994, p. 9-20.

.; MULLER, P. L'état en action. Paris: PUF, 1987.

KAGEYAMA, A. et al. O novo padrão agrícola brasileiro: do complexo rural aos complexos agroindustriais. In: DELGADO, G. (Org.). Agricultura e políticas públicas. Brasília (DF): IPEA, v. 1, 1990, p. 113-223.

LAMARCHE, H. A agricultura familiar II: do mito à realidade. Campinas (SP): Editora da UNICAMP, 1999.

. Aagricultura familiar I: uma realidade multiforme. Campinas (SP): Editora da UNICAMP, 1993.

MAHONEY, J. Path-dependent explanations of regime change: Central America in comparative perspective. Studies in comparative international development, v. 6, n. 1, 2001.

MALUF, R. Mercados agroalimentares e a agricultura familiar no Brasil: agregação de valor, cadeias integradas e circuitos regionais. Ensaios FEE, P. Alegre, v. 25, n. 1, p. 299-322, 2004.

. Segurança alimentar e nutricional. Petrópolis (RJ):

Vozes, 2007.

MARQUES, E. C. Estado e redes sociais: permeabilidade e coesão nas políticas urbanas no Rio de Janeiro. São Paulo (SP): Editora Revan: FAPESP, 1999.

MARQUES, P. E. M. Concepções concorrentes em torno das políticas públicas de apoio à agricultura familiar: uma releitura sobre a construção do PRONAF. In: Congresso da Sociedade Brasileira de Economia, Administração e Sociologia Rural, 42, 2004, Cuiabá (MT), Anais... Cuiabá (MT): SOBER, 2004.

MATTEI, L. PRONAF 10 anos: mapa da produção acadêmica. Brasília (DF): MDA, 2006.

. A reforma agrária brasileira: evolução do número de famílias assentadas no período pósredemocratização do país. Estudos Sociedade $e$ Agricultura, v. 20, n. 1, 2012, p. 301-325.
. O papel e a importância da agricultura familiar no desenvolvimento rural brasileiro contemporâneo. Revista Econômica do Nordeste, v. 45, n. 2, p. 1-09, 2014.

MEDEIROS, L. S. Reforma agrária de mercado e movimentos sociais: aspectos da experiência brasileira. ComCiência, Campinas, v. 44, 2003.

Sem terra, "assentados", "agricultores familiares": considerações sobre os conflitos sociais e as formas de organização dos trabalhadores rurais brasileiros. In: GIARRACCA, N. Una nueva ruralidad en América Latina? Buenos Aires: CLACSO, 2001.

MENEZES, F. Participação social no Fome Zero: a experiência do CONSEA. In: GRAZIANO DA SILVA, J., DEL GROSSI, M.E. e FRANÇA, C.G. Fome Zero: a experiência brasileira. Brasília (DF): MDA, 2010, p.247-264.

MIELITZ NETTO, C.G.A. Agricultura familiar no contexto das políticas públicas brasileiras. In: MANZANAL, M. e NEIMAN, G. Las agriculturas familiares del Mercosur: trayectorias, amenazas y desafios. Buenos Aires: CICCUS, 2010, p. 61-77.

A política agrícola brasileira, sua adequação e sua funcionalidade nos vários momentos do desenvolvimento nacional. In: BONNAL, P. e LEITE, S.P. Análise comparada de políticas agrícolas: uma agenda em transformação. Rio de Janeiro (RJ): Cirad/Mauad X, 2011, p. 221-251.

MÜLLER, A.L. A construção das políticas públicas para a agricultura familiar no Brasil: o caso do Programa de Aquisição de Alimentos. Dissertação (Mestrado em Desenvolvimento Rural) - Programa de Pós-Graduação em Desenvolvimento Rural (PGDR/UFRGS). Porto Alegre (RS), 2007.

MULLER, P. Esquisse d'une théorie du changement dans l'action publique: structures, acteurs e cadres cognitifs. Revue française de sciense politique, v.55, n.1, p. 155-187, 2005.

. Les politiques publiques. 7. ed. Paris: PUF, 2008.

NAVARRO, Z. e CAMPOS, S. K. A "pequena produção rural" no Brasil. In: CENTRO DE GESTÃO E ESTUDOS ESTRATÉGICOS (CGEE). A pequena produção rural e as tendências do desenvolvimento agrário Brasileiro: ganhar tempo é possível? Brasília: CGEE, 2013, p. 13-27.

NIEDERLE, P. A. Compromissos para a qualidade: projetos de indicação geográfica para vinhos no Brasil e na França. Tese (Doutorado de Ciências Sociais em Desenvolvimento, Agricultura e Sociedade) Programa de Pós-Graduação de Ciência Sociais em 
Desenvolvimento, Agricultura e Sociedade (CPDA/ UFRRJ). Rio de Janeiro (RJ), 2011.

ORGANIZAÇÃO DAS NAÇÕES UNIDAS PARA AGRICULTURA E ALIMENTAÇÃO (FAO)/ INSTITUTO NACIONAL DE COLONIZAÇÃO E REFORMA AGRÁRIA (INCRA). Diretrizes de política agrária e desenvolvimento sustentável para a pequena produção familiar. Brasília (DF): FAO/INCRA, 1994.

PALIER, B. e SUREL, Y. Les "trois I" et l'analyse de l'État en action. Revue française de science politique, v. 55, n. 1, p. 07-32, 2005.

PELIANO, A.M.M. Assistência Alimentar nas políticas governamentais. Revista de política agrícola, ano X, n. 1, 2001.

PEREIRA, J.M.M. O modelo de reforma agrária de mercado do Banco Mundial em questão: o debate internacional e o caso brasileiro. Teoria, luta política e balanço de resultados. Dissertação (Mestrado de Ciências Sociais em Desenvolvimento, Agricultura e Sociedade) Programa de Pós-Graduação de Ciência Sociais em Desenvolvimento, Agricultura e Sociedade (CPDA/ UFRRJ). Rio de Janeiro (RJ), 2004.

PICOLOTTO, E. L. As mãos que alimentam a nação: agricultura familiar, sindicalismoepolítica. Tese(Doutorado de Ciências Sociais em Desenvolvimento, Agricultura e Sociedade) - Programa de Pós-Graduação de Ciência Sociais em Desenvolvimento, Agricultura e Sociedade (CPDA/UFRRJ). Rio de Janeiro (RJ), 2011.

PIERSON, P. Public policies as institutions. In: Yale Conference on Crafting and Operating Institutions, New Haven, 2003. Anais... New Haven: Yale University, 2003.

SALLUM JR. B. Metamorfoses do Estado brasileiro no final do século XX. Revista brasileira de ciência sociais, v. 18, n. 52, p. 35-54, 2003.

SANTOS, F. P. Coalizões de interesses e a configuração política da agricultura familiar no Brasil. Tese (Doutorado em Administração Pública e Governo) - Escola de Administração de Empresas de São Paulo (FGV-SP). São Paulo (SP), 2011.

SAUER, S. e PERREIRA, J. M. A reforma agrária de mercado do Banco Mundial no Brasil. Revista Proposta, Rio de Janeiro, v. 107/10, p. 114-119, 2005.

SCHMITT, C.J. A CUT dos colonos: histórias da construção de um novo sindicalismo no campo no
Rio Grande do Sul. In: NAVARRO, Z. Política, protesto e cidadania no campo: as lutas sociais dos colonos e dos trabalhadores rurais do Rio Grande do Sul. Porto Alegre (RS): Ed. da Universidade, 1996, p. 189-226.

SCHNEIDER, S. A pluriatividade na agricultura familiar. Porto Alegre (RS): Editora da UFRGS, 2003.

. Situando o desenvolvimento rural no Brasil: o contexto e as questões em debate. Revista de economia politica, v. 30, n. 3, p. 511-531, 2010.

SCHNEIDER, S., SHIKI, S. e BELIK, W. Rural development in Brazil: overcoming inequalities and building new markets. Rivista di economia agraria, a. LXV, n. 2, p. 225-259, 2010.

SILVA, M.K.S. e SCHMITT, C.J. Políticas em rede: uma análise comparativa das interdependências entre o Programa de Aquisição de Alimentos e as redes associativas no Rio Grande do Sul e na Bahia. In: Encontro Anual da ANPOCS, 36, 2012, Águas de Lindóia (SP), Anais... Águas de Lindóia (SP): ANPOCS, 2012.

SUREL, Y. L'intégration européenne vue par l'approche cognitive et normative des politiques publiques. Revue française de science politique, v. 50, n. 2, p. 235-254, 2000.

TAKAGI, M. A implantação da política de segurança alimentar e nutricional no Brasil: seus limites e desafios. Tese (Doutorado em Economia) - Instituto de Economia (IE/UNICAMP). Campinas (SP), 2006.

TRICHES, R.M. e GRISA, C. Entre mudanças e conservadorismos: uma análise dos Programas de Aquisição de Alimentos (PAA e PNAE) a partir da retórica da intransigência. In: Congresso da Sociedade Brasileira de Economia, Administração e Sociologia Rural, 52, 2014, Goiânia. Anais... Goiânia (GO): SOBER, 2014.

VEIGA, J.E. O desenvolvimento agrícola: uma visão histórica. São Paulo (SP): Editora da Universidade de São Paulo/Hucitec, 1991.

VILELA, S.L.O. Qual política para o campo brasileiro ? (Do Banco Mundial ao PRONAF: a trajetória de um novo modelo?). In: Congresso da Sociedade Brasileira de Economia e Sociologia Rural, 35, 1997, Natal (RN), Anais... Natal (RN): SOBER, 1997.

WILKINSON, J. Mercados, Redes e Valores. Porto Alegre: UFRGS Editora, 2008. 